\title{
Assessing Infirmary Innovative Management: Relating Service Quality and Innovativeness
}

\author{
Thilageswary, A. ${ }^{1}$, Komathi, M. ${ }^{l}$ Subaashnii,.$^{2}$ \\ ${ }^{1}$ School of Management, Faculty of Business Management, Asia Pacific University of Technology \& \\ Innovation (APU), Technology Park Malaysia, 57000, Bukit Jalil, Malaysia, \\ ${ }^{2}$ Faculty of Business Management, University Tunku Abdul Rahman, Sg. Long, Malaysia
}

\begin{abstract}
Organizations are continuously facing the challenge in managing employees not just the technology. This challenge is absolutely unavoidable because there is an implication towards the growth and profitability of an organization. One industry face the dual dynamic technology and people challenge is the hospital management. The purpose of this review is to make a look back on the importance of innovation in the hospital management setting. The end outcome of service quality is argued that innovativeness can lead to service productivity of employee especially in hospital setting. The concept of innovativeness emerges from innovation among employees behaviour in the organizational setting. This paper recommend the need of future study in understanding service quality through innovative behaviour. However, innovative behaviour can only be achieved with the existence of innovative management practices.
\end{abstract}

Key words: Organizational Innovativeness, Service Quality

\section{INTRODUCTION}

Competitive pressure externally and internally drives management to reevaluate new innovations [1]. Successful organizations strive for continuous innovation [2]. Drucker [3] explained that a successful innovative strategy is based on knowing customers and acquiring new knowledge. Innovation is necessary for long-term survival and success [4-5]. Significant innovation responds to the environment to achieve improved performance and sustainability [6]. Creativity is also needed for innovation to occur in organizations. Creativity refers to the invention of novel philosophies [7]. Creativity and innovation are interrelated; thus, these concepts are used interchangeably [8].

Accordingly, innovation is an important empirical construct. Many theories and concepts on innovation have been discussed and synthesized to understand this construct's extent and contribution to organizations. Innovation and innovativeness can be used interchangeably. Many scholars define innovation to explain innovativeness [9]. However, all scholars (e.g., Wang and Ahmed [4], Rowley
[10], Damanpour [11], Myers \& Marquis as cited in Tohidi et al, [9] have a common definition of innovation: this process involves changes or new ideas in whatever practice that occurs in an organization, be it behavior, services, product, or process. Joseph Schumpeter [12] was one of the pioneers who elaborated on innovation theory. Innovativeness is necessary for organizational competitiveness [9] and is also a fact claimed by many scholars. Innovation can be viewed from various perspectives and measurements [13-17] [18, p.47] referred to organizational innovativeness as an aspect of organizational culture. Damanpour [11] and Hult et al. [19] defined innovativeness as the capability to make known to some new processes, products or ideas in an organization."

"Innovativeness refers to corporate environment that promotes and supports novel ideas, experimentation and creation process that may lead to new products, techniques, or technologies..." [20, p.5). "Innovation is something about newness that is doing new things but creativity is about bringing something into thinking up new things..." [21, p.2]. Schumpeter [12] identified product, market, and process in validating innovation scale. By contrast, 
Miller and Frisen [17] identified four dimensions, namely, product, process, behavior, and strategy, used in Wang and Ahmed [4] in validating innovation scale. Schumpeter's theory of innovation comprises new product, market, organization, and technology [22]. Innovativeness is the "capability to develop and introduce products or process..." [23]. "Innovativeness is also seen as ability of organization to novel ideas, to accept innovation and to support idea generation..." [24]. Innovation can be a new product or service, a new production process, or a new structure or administrative system [19]. Organizational/hospital innovation is defined as "the notion of openness to new ideas as an aspect of a firm's culture" [18, p. 44], as cited in Kunz et al, [25]. Kunz et al, [25] elaborated that organizational innovativeness reflects foremost perceptions of internal stakeholders (e.g., employees and managers). Innovation relates "to some form of specific change that is new and that leads to what is in some sense a better accomplishment of goals at a system level..." [26; p. 28]. The underlying theories of innovation are logistical functional form and economic theories [27].

The concept of innovation is rooted from diffusion theory developed by Rogers [27]. The diffusion of innovation is persuaded toward innovation, adoption, implementation, and confirmation of the design to adopt innovation [28]. Considering that innovativeness can be viewed from various perspectives, the diffusion of innovation proposed by Rogers [27] reinforces the study purpose. The measurement used is based on the methods developed by famous innovative scholars, including Miller and Friesen [17], Johanessen [15] and Hult [19]. The innovativeness perspective underpins the cultivation of the innovative behaviors of employees. A considerable amount of empirical evidence has been used to measure organizational innovativeness $[1,28]$.

\section{INNOVATIVENESS IN PRACTICE}

The adoption of new technology is important to acquire and adopt innovations. Technology innovation was also studied in hospital settings, where organizational context (organizational size, slack resource, and age) has an effect [30]. On another notion, innovation implies the generation, reception, and execution of new ideas, processes, products, and services [6]. Conceptualized organizational innovativeness as behavioral is the rate of innovation adoption and organizational willingness to change [18], which is based on diffusion innovation. Accordingly, diffusion is a process where innovation communicates new ideas among a social system's members through certain channels over time [27].
Skerlavaj et al [1] measured innovativeness in three categories, namely, innovative culture, technical, and administrative. The current study investigates innovative culture as organizational innovativeness. Innovation is measured by product, process, and administrative system [31]], and depends on how managers acquire and act on market intelligence. Learning orientation was determined to have an effect on innovativeness [6, 19]. Kunz et al [25, p. 817] further elaborated that organizational innovativeness reflects the primary perception of internal stakeholders (e.g., employees and managers). Organizational behavior adopts new procedures when an organization encounters changes. Innovation may take different forms, such as product, process, radical or incremental, technical, and administrative innovations. Innovation dimension is varied and dynamic based on the literature [4-5]. Calantone [6] identified the degree of newness and Johanessen et al, [32] identified six different types of newness, namely, developing new products, new services, new methods of production, opening new markets, new sources of supply, and methods of organization. Subramaniam [16] emphasized that organizational innovativeness involves technical and administrative functions. A study was conducted on a considerably narrowed perspective of innovativeness, in which Wang and Ahmed [4] presented multidimensional conceptualization. However, Ellonen et al [5] claimed that product and market dimensions can be considered in a single dimension because was not extensively studied on these product and market dimensions. Wang and Ahmed [4] expansion of work showed that the underlying factors involve behavioral changes, processes, and strategies rather than merely product innovativeness. They created work based on five dimensions of innovative capability for organizational products, markets, processes, strategies, and behavior innovativeness. The items for organizational innovativeness used a seven-point Likert scale, ranging from $1=$ strongly agree to $7=$ strongly disagree. The reliability alpha for all the 20 items is 0.9091 . Content and convergent validity of the measurement also prove the best fit for the model.

Innovation can also occur in multiple forms in hospital [33]. The advantages of "newness" in this comprehensive organizational innovativeness include being quantifiable, covers various aspects of innovation, and measures an organization's capability to develop new products/services [4]. Overall, innovative scale building has developed a comprehensive use of innovative dimension comprising five factor measurements, namely, product, market, process, behavior, and strategy. The behavioral innovativeness by Hurley snd Hult [18] and Ellonen et al, [5], in which innovativeness 
is defined as demonstration of individuals, group and management that empowers the establishment of an innovative culture which is the whole internal accessibility to new ideas and innovation." The Porter [34] model states that an act of innovation is required to deliver superior value to customers [20]. Innovation is also practiced in the healthcare industry because this process is viewed as linked to several approaches [33]: production functions; set of technological and bio-pharma logical capabilities (medical innovation; information systems, and providers of complex services and healthcare system hubs, the fourth group innovations based on service and service relationship. Innovation is not merely an information system/technology or even production function, in which additional effort is necessary to satisfy customers and their families and relatives.

Schumpeter [12] defined five concepts of innovation, namely, new products, new methods or production, opening new markets, new sources of raw materials, and establishing new organizations (as cited in Slatten [8]). It is explained that the introduction of new products and the continuous improvement of an organization lead to development. The process of serving a customer is an innovative behavior [8]. Gallouj [35] called this process ad hoc innovation, which is produced when providing services and new solutions based on experience. Innovative behavior is assumed to contribute positively to service performance on customers [8]. To achieve innovative behavior, creativity needs to be embedded among employees. An innovative culture stimulates the innovative behavior [1]. "Innovative behavior is application or implementation of novel ideas in the work role, creative engagement is more fundamental in its nature as it focuses on the input to innovative behavior..." [8, p. 271]. Mafabi et al [36] measured the instrument on structural, process, and competence innovations. They studied innovation as a mediator between the variables of knowledge management and organization resilience. Innovation is also studied as a process, result, and different types of innovation (e.g., technical, process, and behavior) [1]. Many scholars generally view innovation as new technology, products/services, and administrative system [35]. Technical innovations include products as introduction of products or services [1,37]. Process innovation is the distribution of delivery services and adoption of new methods or procedures. Innovation is also categorized as a social or behavioral process $[1,27]$. Ho [38] measured innovation as a mediator that comprises technological, market, and administrative aspects. Technological innovation comprises product processes and services, whereas market innovation refers to price, promotion, and place. Alternatively, administrative innovation refers to strategy, structure, system, and culture. Generally, innovation is used to survive external environmental challenges and ensure long-term success. Companies capable of innovating respond to external challenges rapidly. However, to summarize innovative culture or behavior [39] (Jong \& Hartog, 2007), perspective was analyzed to support the organizational learning concept for the current study. Furthermore, the present study attempts to determine whether innovation is cultivated among employees to determine value creation for stakeholders. Innovativeness in employees leads to innovation. The measurement for this research is adapted based on Cerne et al [29] and Rhee et al [40], which were grounded on Hurley [18]. The five items were utilized and confirmatory factor analysis confirmed that the unidimensional with coefficient is significant.

\section{LINKING SERVICE QUALITY AND INNOVATIVENESS}

Innovation is known to contribute to business performance where it is significant and has positive relationship [19, 41]. Moreover, innovation is considered a prerequisite for a firm's success and survival [1, 40-41]. Many scholars have studied the link between innovativeness and performance $[6,19$, 42]. Accordingly, innovativeness can only contribute to performance. Particularly in hospitals that are considered complex [33]. Organizational innovativeness in hospitals also depends on management abilities and innovative decisions, and should be emphasized on customer focus strategies [43]. Innovation is seen from a technical and process innovative perspective [37]. Process innovation involves improving methods, distribution, or delivery of service.

Organizational innovativeness enhances customer service and financial performance. Many empirical studies have demonstrated positive results between innovation and performance [1, 41]. Firm performance is categorized as quality, innovation, and operational performance. Quality and innovation are considered a parallel pair for management excellence [44]. Customer service performance, which also refers to service quality, is linked with organizational performance. Innovativeness mediates customer orientation and customer service performance. In a study in Marmara, Turkey, innovativeness as a mediating role was determined to increase performance directly.

\section{CONCLUSION}

Innovation in hospitals is linked to several approaches, such as providers, services, and service relationships, because the need is more than merely 
satisfying customers, families, and relatives [33]. A study identified institutional structure-enhanced organizational performance through knowledge sharing because healthcare is a knowledge-intensive industry. These researchers specified that punitive practice and good leadership are related to patient safety. Ideas and empirical findings identified organizational innovativeness; however, service quality has yet to be completely studied empirically. Understanding the effect of how employee innovative behavior in organization fulfills services provided to the customer is important.

Innovation and service quality has important managerial implication. It has much avenues for future research in making service better in hospitals. Innovation has been highlighted as inevitable to organizational productivity and customer value. Though there has been relatively many studies on innovativeness but focus has to be on more hospital management. Along with the advancement of technology, changes is dynamic. As such, expansion on building innovative management is appropriate. Studies should look into this connectivity towards creating a typology of innovative management in the hospital setting. The need for effective healthcare management is a necessity globally.

\section{REFERENCES}

[1] Škerlavaj, M., Song, J. H., \& Lee, Y. (2010). Organizational learning culture, innovative culture and innovations in South Korean firms. Expert Systems with Applications, 37(9), 6390

6403.http://doi.org/10.1016/j.eswa.2010.02.0 80

[2] Auh, S., \& Menguc, B. (2005). Top management team diversity and innovativeness: The moderating role of interfunctional coordination. Industrial Marketing Management, 34(3), 249261.http://doi.org/10.1016/j.indmarman.2004. 09.005 .

[3] Drucker, P.F., 1985. The discipline of innovation. Harvard business review, 63(3), pp.67-72.

[3] Wang, C. L., \& Ahmed, P. K. (2004). The development and validation of the organisational innovativeness construct using confirmatory factor analysis. European journal of innovation management, 7(4), 303-313.

[4] Ellonen, R., Blomqvist, K., \& Puumalainen, K. (2008). The role of trust in organisational innovativeness. European Journal of Innovation Management, 11(2), 160-181.

[5] Calantone, R. J., Cavusgil, S. T., \& Zhao, Y. (2002). Learning orientation, firm innovation capability, and firm performance. Industrial Marketing Management, 31(6), 515-524.

[6] Honey, P., \& Mumford, A. (1992). The manual of learning styles.

[7] Slåtten, T., Svensson, G., \& Sværi, S. (2011). Empowering leadership and the influence of a humorous work climate on service employees' creativity and innovative behaviour in frontline service jobs. International Journal of Quality and Service Sciences, 3(3), 267-284. http://doi.org/10.1108/17566691111182834

[8] Tohidi, H., Seyedaliakbar, S. M., \& Mandegari, M. (2012). Organizational learning measurement and the effect on firm innovation. Journal of Enterprise Information Management, 25(3), 219-245. pp.219 - 245 doi:http://dx.doi.org/10.1108/1741039121122 4390

[9] Rowley, J. (2010). Should your library have an innovation strategy? Library Management, 32 (4/5)251-65.

[10] Damanpour, F. (1991). Organizational Innovation: A Meta-Analysis Of Effects Of Determinants and Moderators. Academy of Management Journal, 34(3), 555-590. http://doi.org/10.2307/256406

[11] Schumpeter, J. A. (1934). The Theory of Economic Development: An Inquiry Into Profits, Capital, Credit, Interest, and the Business Cycle. Transaction Publishers.

[12] Hussein, N., Mohamad, A., Noordin, F., \& Ishak, N. A. (2014). Learning organization and its effect on organizational performance and organizational innovativeness: a proposed framework for Malaysian public institutions of higher education. Procedia-Social and Behavioral Sciences, 130, 299-304

[13] Garcia, R., \& Calantone, R. (2002). A critical look at technological innovation typology and innovativeness terminology: a literature review. Journal of product innovation management, 19(2), 110-132.

[14] Johanessen, O. (2000). Job demands, perceptions of effort-reward fairness and innovative work behaviour. Journal of Occupational and Organizational Psychology, 73(3), 287-302. http://doi.org/10.1348/096317900167038

[15] Subramanian, A., \& Nilakanta, S. (1996). Organizational innovativeness: exploring the relationship between organizational determinants of innovation, types of innovations, and measures of organizational performance. Omega, 24(6), 631-647.

[16] Miller, D., \& Friesen, P. H. (1983). Successful and Unsuccessful Phases of the Corporate Life Cycle. Organization Studies, 4(4), 339-356. http://doi.org/10.1177/017084068300400403] 
[17] Hurley, R. F., \& Hult, G. T. M. (1998). Innovation, market orientation, and organizational learning: an integration and empirical examination. The Journal of marketing, 42-54.

[18] Hult, G. T. M., Hurley, R. F., \& Knight, G. A. (2004). Innovativeness: Its antecedents and impact on business performance. Industrial Marketing Management, 33(5), 429-438.

[19] Weerawardena, J. (2013). Exploring the role of market learning capability in competitive strategy. European Journal of Marketing. http://doi.org/10.1108/03090560310459023

[20] Clegg, B. (1999). Creativity and Innovation for Managers. Routledge.

[21] Anderson, N., Potočnik, K., \& Zhou, J. (2014). Innovation and creativity in organizations: A state-of-the-science review, prospective commentary, and guiding framework. Journal of Management, 40(5), 1297-1333.

[22] Azadegan, A. and Dooley, K.J. (2010) Supplier Innovativeness, Organizational Learning Styles and Manufacturer Performance: An Empirical Assessment. Journal of Operations Management, 28, 488505.

[23] Hanvanich, S., Sivakumar, K., \& M. Hult, G. T. (2006). The relationship of learning and memory with organizational performance: the moderating role of turbulence. Journal of the Academy of Marketing Science, 34(4), 600612.

[24] Kunz, W., Schmitt, B. and Meyer, A. (2011), How does firm innovativeness affect the consumer?, Journal of Business Research, Vol. 64 No. 8, pp. 816-823.

[25] Ellström, P. E. (2010). Practice-based innovation: a learning perspective. Journal of Workplace Learning, 22(1/2), 27-40.

[26] Brewer, G. D. (1980). On the theory and practice of innovation. Technology in Society, 2(3), 337-363.

[27] Surry, D. W., \& Farquhar, J. D. (1997). Diffusion theory and instructional technology. Journal of Instructional Science and Technology, 2(1), 24-36.

[28] Černe, M., Jaklič, M., Škerlavaj, M., Aydinlik, A. Ü., \& Polat, D. D. (2012). Organizational learning culture and innovativeness in Turkish firms. Journal of Management \& Organization, 18(02),

193-219. http://doi.org/10.1017/S183336720000095X

[29] Nystrom, P. C., Ramamurthy, K., \& Wilson, A. L. (2002). Organizational context, climate and innovativeness: adoption of imaging technology. Journal of Engineering and Technology Management, 19(3-4), 221-247.

[30] Manu, F. A. (1992). Innovation orientation, environment and performance: A comparison of US and European markets. Journal of
International Business Studies, 23(2), 333359.

[31] Johannessen, J.A., Olsen, B. \& Lumpkin, G.T. (2001) Innovation as newness: What is new, how new, and new to whom? European Journal of Innovation Management, 4, 20-31

[32] Djellal, F., \& Gallouj, F. (2005). Mapping innovation dynamics in hospitals. Research Policy, 34(6), 817-835. http://doi.org/10.1016/j.respol.2005.04.007

[33] Porter, M.E., 1990. The Competive Advantage of Nations Free Press. New York.

[34] Gallouj, F., \& Weinstein, O. (1997). Innovation in services. Research policy, 26(45), 537-556.

[35] Mafabi, S., Munene, J., \& Ntayi, J. (2013). Knowledge management and organisational resilience. Journal of Strategy and Management. http://doi.org/10.1108/17554251211200455

[36] Jiménez-Jimenez, D., Valle, R. S., \& Hernandez-Espallardo, M. (2008). Fostering innovation: the role of market orientation and organizational learning. European Journal of Innovation Management, 11(3), 389-412.

[37] Ho, L. A. (2011). Meditation, learning, organizational innovation and performance. Industrial Management \& Data Systems, 111(1), 113-131.

[38] Baker, W. E., \& Sinkula, J. M. (1999a). The Synergistic Effect of Market Orientation and Learning Orientation on Organizational Performance. Journal of the Academy of Marketing Science, 27(4), 411-427. http://doi.org/10.1177/0092070399274002

[39] De Jong, J.P. and Den Hartog, D.N., 2007. How leaders influence employees' innovative behaviour. European Journal of innovation management, 10(1), pp.41-64.

[40] Prajogo, D. I. (2016). The strategic fit between innovation strategies and business environment in delivering business performance. International Journal of Production Economics, 171, 241-249.

[41] Garcia-Morales, V. J., Llorens-Montes, F. J., \& Verdú-Jover, A. J. (2006). Antecedents and consequences of organizational innovation and organizational learning in entrepreneurship. Industrial Management \& Data Systems, 106(1), 21-42.

[42] Thakur, R., Hsu, S. H., \& Fontenot, G. (2012). Innovation in healthcare: Issues and future trends. Journal of Business Research, 65(4), 562-569.

[43] Zehir, C., Ertosun, Ö. G., Zehir, S., \& Müceldilli, B. (2012). Total Quality Management Practices' Effects on Quality Performance and Innovative Performance. Procedia - Social and Behavioral Sciences, 41, 
Thilageswary / International Journal of Business and Management, 2 (3) 2018, Pages: 40-45

273-280.

http://doi.org/10.1016/j.sbspro.2012.04.031.

[44] Theoharakis, V., \& Hooley, G. (2008).

Customer orientation and innovativeness:

Differing roles in New and Old Europe.

International Journal of Research in

Marketing, 25(1), 69-79. 